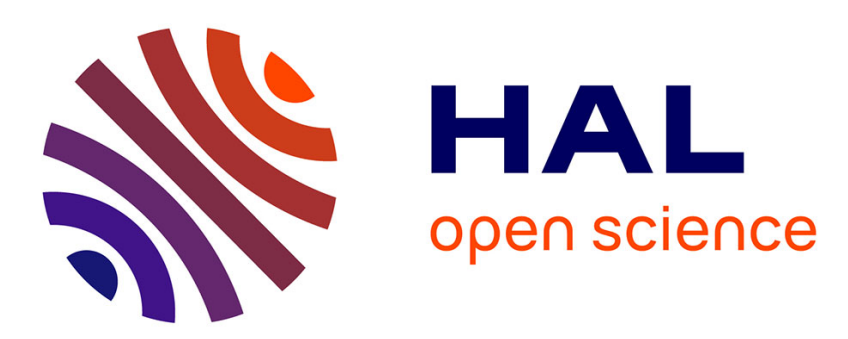

\title{
Structural-elastic relationships of $\mathrm{Zr}-\mathrm{TL}(\mathrm{TL}=\mathrm{Cu}$, Co, $\mathrm{Ni}$ ) thin films metallic glasses
}

\author{
M. Apreutesei, P. Djemia, Laurent Belliard, G. Abadias, C. Esnouf, Alain
} Billard, Philippe Steyer

\section{- To cite this version:}

M. Apreutesei, P. Djemia, Laurent Belliard, G. Abadias, C. Esnouf, et al.. Structural-elastic relationships of $\mathrm{Zr}-\mathrm{TL}(\mathrm{TL}=\mathrm{Cu}, \mathrm{Co}, \mathrm{Ni}$ ) thin films metallic glasses. Journal of Alloys and Compounds, 2016, 707, pp.126-131. 10.1016/j.jallcom.2016.12.208 . hal-01427134

\section{HAL Id: hal-01427134 \\ https://hal.sorbonne-universite.fr/hal-01427134}

Submitted on 5 Jan 2017

HAL is a multi-disciplinary open access archive for the deposit and dissemination of scientific research documents, whether they are published or not. The documents may come from teaching and research institutions in France or abroad, or from public or private research centers.
L'archive ouverte pluridisciplinaire HAL, est destinée au dépôt et à la diffusion de documents scientifiques de niveau recherche, publiés ou non, émanant des établissements d'enseignement et de recherche français ou étrangers, des laboratoires publics ou privés. 
Structural-elastic relationships of $\mathrm{Zr}-\mathrm{TL}(\mathrm{TL}=\mathrm{Cu}, \mathrm{Co}, \mathrm{Ni})$ thin films metallic glasses

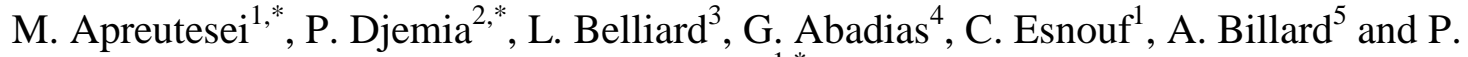 \\ Steyer ${ }^{1, *}$ \\ ${ }^{1}$ Université de Lyon, INSA-Lyon, MATEIS UMR CNRS 5510, 7 avenue Jean Capelle, 69621 Villeurbanne \\ Cedex, France \\ ${ }^{2}$ LSPM-CNRS, Université Paris 13, Sorbonne Paris-Cité, 99 Avenue J.B. Clément 93430 Villetaneuse, France, \\ ${ }^{3}$ UPMC-Institut des NanoSciences de Paris, 4 place Jussieu 75252 Paris cedex 05, France, \\ ${ }^{4}$ Département Physique et Mécanique des Matériaux, Institut P', CNRS-Université de Poitiers-ENSMA, SP2MI - \\ Téléport 2, BP 30179, F86962 Futuroscope-Chasseneuil, France, \\ ${ }^{5}$ Institut FEMTO-ST, CNRS, UTBM, Univ. Bourgogne Franche-Comté, Site de Montbéliard, F-90010 Belfort \\ Cedex, France
}

*corresponding authors: mihaiapr@gmail.com, djemia@univ-paris13.fr and philippe.steyer@insa-lyon.fr

\begin{abstract}
In this study, we investigated the structural and elastic properties of $\mathrm{Zr}$ - TL (late transition metal $\mathrm{TL}=\mathrm{Cu}, \mathrm{Co}, \mathrm{Ni}$ ) thin films metallic glasses $(\mathrm{TFMG})$ deposited by dc magnetron co-sputtering from pure TL targets in Ar plasma discharge. The influence of the deposition parameters on the microstructure, chemical composition and elastic properties of the thin films has been explored. Advanced non-destructive techniques such as the picosecond ultrasonics and the Brillouin light scattering were employed to selectively measure the longitudinal $V_{\mathrm{L}}$ and the transversal $V_{\mathrm{T}}$ sound velocities, leading to the determination of the elastic constants $C_{11}, C_{44}$, respectively. From these data sets, the elastic constants of metastable amorphous single elements $a-\mathrm{Zr}, a-\mathrm{Cu}, a$-Co and $a$-Ni have been extrapolated. Some relationships between elastic moduli (Young's modulus $E$ and shear modulus $G=C_{44}$ ) and the structural state either crystalline or amorphous are established. Predicted ductility/brittleness character was emphasized based on the Blackman's diagram, Pugh's ratio and the Pettifor criteria. Equivalently, the newly introduced $\delta$ parameter termed as 'the cooperation parameter' and related uniquely to the Poisson's ratio $v$, confirmed the improvement of ductility with TL alloying.
\end{abstract}

\title{
Keywords:
}

Thin films, metallic glasses, ultrasonics, elasticity, mechanical properties 


\section{Introduction}

Since the metallic glasses were first discovered in 1960 [1], researchers are interested in their unique atomic packing structures [2] mechanical [3], electronic [4], and magnetic [5] properties. The initial limitation in preparing bulk metallic glasses (BMGs) by rapid quench techniques was gradually overcome by coupling appropriate elements with different atomic sizes based on the empirical rules pointed out by Inoue [6]. Many new amorphous alloys based on early transition (TE) - late transition (TL) alloying metals, such as $\mathrm{Zr}-\mathrm{Ni}-\mathrm{Cu}-\mathrm{Al}$ [7], Zr-Ti-Cu [8], Mg-Cu-Gd [9] and Ti-Cu-Ni-Sn [10], have been fabricated in ribbon or bulk type with diameters greater than a few $\mathrm{mm}$.

Employing thin film technology routes, such as physical vapor deposition (PVD) is an alternate way to avoid the precipitation of the immiscible elements and produce thin film metallic glasses (TFMG) with over-saturated alloy concentrations. The solubility of immiscible elements and glass forming composition range using PVD processes are both much higher, compared with the liquid quenching process used for bulk or ribbon amorphous alloys. Among them, the $\mathrm{Zr}-\mathrm{Cu}, \mathrm{Zr}-\mathrm{Ni}$ and $\mathrm{Zr}$-Co systems belong to the immiscible TE-TL category which has good glass-forming ability, as previously observed in BMG [11-13] and TFMGs [14-16]. Depending on the concentration of TL elements in the matrix, homogeneous nanocrystalline and amorphous phases or mixed phases were identified.

Relationship between structural and mechanical properties remains not enough documented for amorphous metal alloys compared to conventional crystalline materials. Some recent studies have contributed to highlight the correlation between density (depending on the composition), hardness, Young's modulus and glass-forming ability (GFA) [17]. The origins of ductility/brittleness and relationship between density, elastic/plastic properties and GFA are the hottest topics in the undergoing research of amorphous alloys. Moreover, the mechanical properties are fundamental input parameters for structural design of micro- or nano-devices. 
However, in comparison to the enormous work done on BMGs, on TFMGs only few studies have been conducted.

In this work, we measured selectively, the two independent elastic constants, $\mathrm{C}_{11}$ and $\mathrm{C}_{44}=\left(\mathrm{C}_{11}-\mathrm{C}_{12}\right) / 2$ (using Voigt notations, the $\mathrm{C}_{\mathrm{IJ}}$ 's relate the stress $\sigma_{\mathrm{ij}}$ and the strain $\varepsilon_{\mathrm{kl}}$ through the Hooke law $\mathrm{s}_{\mathrm{I}}=\mathrm{C}_{\mathrm{IJ}} \mathrm{e}_{\mathrm{J}}$, with $\mathrm{e}_{1}=\varepsilon_{11}, \mathrm{e}_{2}=\varepsilon_{22}, \mathrm{e}_{3}=\varepsilon_{33}, \mathrm{e}_{4}=2 \varepsilon_{23}, \mathrm{e}_{5}=2 \varepsilon_{13}$ and $\mathrm{e}_{6}=2 \varepsilon_{12}$ ), of a series of elastically isotropic Zr-TL TFMG by the original combination of non-destructive picosecond ultrasonics (PU) [18, 19] and Brillouin light scattering (BLS) [20-21] techniques. They are well adapted for an accurate characterization of the elastic properties of Zr-TL thin films, as demonstrated previously for metastable Mo-Si [18] and nitrides [19] alloys thin films. From these measurements, the elastic moduli of the films have been calculated and ductility/brittleness behavior was predicted.

\section{Experimental}

\subsection{Thin films growth and structural properties}

The Zr-TL thin films were deposited on Si substrates by a direct-current co-sputtering process in a 40-liter cylinder Alcatel $450 \mathrm{SCM}$ sputtering reactor. . The $\mathrm{TL}=\mathrm{Cu}$, $\mathrm{Co}$ and $\mathrm{Ni}$ targets were powered using a MDX500 generator in the range $0.1-1.5 \mathrm{~A}$ at a pressure around $0.5 \mathrm{~Pa}$. More details about films deposition can be found elsewhere [15, 22]. Three thin film series were produced: $\mathrm{Zr}-\mathrm{Cu}, \mathrm{Zr}-\mathrm{Co}$ and $\mathrm{Zr}-\mathrm{Ni}$, and the content of $\mathrm{TL}$ atoms varied by changing the respective cathode currents. The $\mathrm{Zr}-\mathrm{Cu}$ system was previously explored in the whole phase diagram, whereas in the current study, for $\mathrm{Zr}-\mathrm{Co}$ and $\mathrm{Zr}-\mathrm{Ni}$ thin films, we restricted the compositions in the range of $\langle 40-80>$ at. \% for the TL element.

The thickness of the thin films and chemical profiles were determined by a Zeiss Supra 55 VP scanning electron microscope (SEM) with energy dispersive X-ray microanalysis (EDX). The thickness ranged between 4 and $6 \mu \mathrm{m}$, so that they can be considered as a semi-infinite 
medium for BLS experiments to measure the shear elastic constant $\mathrm{C}_{44}$ of the film. The common required structural information to extract elastic constants from PU and BLS measurements of sound velocities is the mass density, $\rho$. It was achieved from a fit of X-ray reflectivity (XRR) scans using an optical model [23].

\subsection{Basic principles about picosecond ultrasonics and Brillouin light scattering}

Only some principles will be recalled in this section while more details about both experiments can be found elsewhere [19]. The PU technique introduced by H. J. Maris in 1980 [24] derives from the well-known optical pump and probe scheme. A femtosecond laser pulse pump beam is absorbed at the sample surface. This absorption generates, by thermal expansion, a longitudinal acoustic wave that propagates through the system, perpendicularly to the free surface. For a monolithic film onto a substrate, sharp reflectivity changes are periodically detected, the so-called echoes, separated by a constant time delay (the time of flight TOF) as in a standard sonar technique.If the thickness $h$ of the layer is known, PU gives a direct access to the longitudinal sound velocity simply defined by $\mathrm{V}_{\mathrm{L}}=2 h / \mathrm{TOF}$, along the normal of the film-plane, where TOF is measured with an accuracy better than 1 ps $[18,19$, 24]. Thus, considering amorphous materials with isotropic elastic properties the result should be the same for the following elastic constants: $C_{11}=C_{22}=C_{33}=\rho V_{L}^{2}$.

In a BLS experiment, a monochromatic incident light beam probes the thermally excited acoustic waves. The BLS spectra were obtained at room temperature in air, with typical acquisition times of $1 \mathrm{~h}$ and $300 \mathrm{~mW}$ of a p-polarized incident light. For opaque films, the scattering mechanism is restricted to the scattering of light by the dynamical corrugation of the free surface by acoustic waves travelling parallel to the film plane [20,25]. For films with thicknesses well above the acoustic wavelength $(\sim 0.3 \mu \mathrm{m})$, we measure the Rayleigh surface wave velocity $(R)$ of the film $[25,26]$ closely related to its transverse velocity $V_{T}=\left(C_{44} / \rho\right)^{1 / 2}$ 
[27]. Also, we can observe a singularity at higher frequency that enables the measurements of $V_{\mathrm{L}}$ by BLS [25].

Once, $V_{\mathrm{L}}$ and $V_{\mathrm{T}}$ are measured, the elastic moduli (shear modulus $G$, Young modulus $E$, bulk modulus $B$ and Poisson ratio $v$ ) can be calculated using the following equations:

$$
\begin{aligned}
& G=\rho V_{T}^{2}=\frac{C_{11}-C_{12}}{2}=C_{44}=\frac{E}{2(1+v)}, \\
& E=\rho\left[V_{L}^{2}-\frac{\left(V_{L}^{2}-2 V_{T}^{2}\right)^{2}}{\left(V_{L}^{2}-V_{T}^{2}\right)}\right]=\mathrm{C}_{11}-\frac{\left(\mathrm{C}_{11}-2 \mathrm{C}_{44}\right)^{2}}{\left(\mathrm{C}_{11}-\mathrm{C}_{44}\right)}, \\
& B=\rho\left(V_{L}^{2}-\frac{4}{3} V_{T}^{2}\right)=C_{11}-\frac{4}{3} C_{44}, \\
& v=\frac{\left(V_{L}^{2}-2 V_{T}^{2}\right)}{2\left(V_{L}^{2}-V_{T}^{2}\right)}=\frac{\mathrm{C}_{11}-2 \mathrm{C}_{44}}{2\left(\mathrm{C}_{11}-\mathrm{C}_{44}\right)} \equiv \frac{1}{2} \frac{\left(3-2 \frac{\mathrm{G}}{B}\right)}{\left(3+\frac{\mathrm{G}}{B}\right)},
\end{aligned}
$$

Other parameters such as the Pugh's ratio $k=\mathrm{G} / \mathrm{B}$ [28], the Cauchy's pressure $p=\mathrm{C}_{12}-\mathrm{C}_{44}$ [29] and the 'cooperation parameter' $\delta=\frac{(1+v)^{2}}{12.65(1-2 v)^{2}}$ [30] will be helpful to discuss the brittleness/ductility predictive properties of our films.

\section{Results and discussion}

The X-ray diffraction (XRD) patterns recorded in $\theta-2 \theta$ configuration for the three film series are reported in figure 1 . They all exhibit scattering peaks in the $37-45^{\circ} 2 \theta$ region, often referred as first sharp diffraction peak or principal diffraction peak, characteristic of amorphous alloys. For all systems, a shift of the broad diffuse-scatter to higher $2 \theta$ angles is observed by increasing the content of TL atoms. This evolution suggests a continuous decrease of the average interatomic distance or equivalent first coordination sphere radius [31]. Moreover, using the Bragg's relation the equivalent lattice spacing (d) for Zr-TL films also decreased from about $2.45 \AA$ to $2.10 \AA$, suggesting different bonding lengths and interatomic interactions that modifies the atomic local ordering. It has been reported by 
simulations that when mixing $\mathrm{Zr}$ and $\mathrm{TL}$ elements $(\mathrm{TL}=\mathrm{Cu}, \mathrm{Ni}, \mathrm{Co})$ the local ordering is organized such as polyhedral-type short and medium range ordering structures controlled by the atomic size ratio and the electronic interactions between the component elements. For instance, for a $\mathrm{Zr}_{70} \mathrm{Cu}_{30}$ alloy the local atomic environment matched to an icosahedral-like around the $\mathrm{Cu}$ atoms and global short range ordering (SRO) structure [32], while for $\mathrm{Zr}_{66.7} \mathrm{Ni}_{33.3}$ alloy around the $\mathrm{Zr}$ atoms a trigonal prism polyhedron dominated with medium range ordering (MRO) structure [33]. For the Zr-Co system, it has been demonstrated by molecular dynamics (MD) simulations that the local structure is quantified as short-range-order [34]. Therefore, based on the studies reported in literature it may be inferred that the local ordering of the $\mathrm{Zr}-\mathrm{TL}(\mathrm{TL}=\mathrm{Cu}, \mathrm{Ni})$ thin films studied here is governed by SRO/MRO structures.

The evolution of XRD patterns of $\mathrm{Zr}-\mathrm{Cu}$ films with increasing $\mathrm{Cu}$ in a wider range of concentration has been reported in a previous paper (see Fig. 2 of Ref. [15]). From this work, the amorphous phase region was identified for $\mathrm{Cu}$ content within the $<30-85$ at. $\%>$ range. Figure 2 presents the mass density evolution as a function of films. From this figure, it can be observed that $\rho$ increases with TL content from $\rho_{\mathrm{Zr}}=6.0 \mathrm{~g} \cdot \mathrm{cm}^{-3}$ to $\sim 8.3 \mathrm{~g} . \mathrm{cm}^{-3}$ for the most alloyed films. In both cases the same trend implies that TL additions continuously move/reorganize the atoms at the local range. Hence, as more TL is added in the amorphous matrix, the distances between the closest neighbors is reduced and the mass density is increased, leading finally to more compact structure. Nevertheless, both extrapolated values are slightly lower than the bulk values of the bulk crystalline $\alpha-\operatorname{Zr}\left(6.52 \mathrm{g.cm}^{-3}\right)$ and crystalline TL single elements $\left(\sim 9 \mathrm{~g} . \mathrm{cm}^{-3}\right) \rho$ remains for TL-rich concentrations below the average mass density calculated from bulk values. It means that films which lie below the Vegard's rule in Fig. 2, are not fully dense compared to the bulk, with a certain degree of porosity not investigated, here. 
PU measurements allow determining values of the $C_{11}$ parameters. For all samples, the $C_{11}$ elastic constant is first measured by PU and then considered as a fixed known parameter in the fitting of the BLS spectra used to evaluate the $\mathrm{C}_{44}$ parameter. As illustrated in figure 3 within the amorphous region, a clear monotonous increase of the shear elastic constant $\mathrm{C}_{44}$ is observed upon incorporation of a TL substituting atom, essentially due to the increase in $\rho$.

For the $\mathrm{Zr}-\mathrm{Cu}$ system, the drop of $\mathrm{C}_{11}$ near the 30 - 35 at. \% region can be attributed to the phase transition from crystalline to amorphous state, as it was similarly observed in Mo-Si system [18], and predicted in Braeckman et al. [31]. Moreover, the $\mathrm{C}_{11}$ constant shows apparent scattering of the data in the amorphous region whereas relative uncertainty in the thickness measurements does not exceed a few percent, and seems to be much more sensitive to changes of local atomic environment related to formation of different type of SRO and different bonding energies, as a function of the $\mathrm{Cu}$ concentration. The scattering in $\mathrm{C}_{44}$ data is always less pronounced as it does not depend on the thickness of these thick films, neither on the substrate. In the case of $\mathrm{Zr}-\mathrm{Cu}$ alloy, the $\mathrm{C}_{44}$ elastic constant increases linearly from 22 $\mathrm{GPa}$ to $35 \mathrm{GPa}$ in the amorphous region. Considering ideal solution behavior [35] of the glassy state, we obtain extrapolated shear modulus for a "hypothetical" amorphous zirconium a-Zr of $17 \mathrm{GPa}$ (well below the polycrystalline value of $33 \mathrm{GPa}$ for hcp $\alpha$-Zr) and $37 \mathrm{GPa}$ for a-Cu (slightly lower than the value of $48 \mathrm{GPa}$ for $\mathrm{fcc}-\mathrm{Cu}$ ). Considering similar ideal solution behavior [35] of glassy $\mathrm{Zr}-\mathrm{Co}$ and $\mathrm{Zr}-\mathrm{Ni}$, we obtain extrapolated shear modulus of $53 \mathrm{GPa}$ for a-Co and $58 \mathrm{GPa}$ for a-Ni. In the case of the second constant, namely $\mathrm{C}_{11}$, we can obtain an extrapolated value for a "hypothetical" amorphous zirconium a-Zr of $84 \mathrm{GPa}$ (well below the polycrystalline value of $141 \mathrm{GPa}$ for hcp $\alpha-\mathrm{Zr}$ ) and $184 \mathrm{GPa}$ for a-Cu, $224 \mathrm{GPa}$ for a-Co and $239 \mathrm{GPa}$ for a-Ni (all slightly below their crystalline phase). The large difference between the values of $\mathrm{C}_{11}$ and $\mathrm{C}_{44}$ for $\mathrm{a}-\mathrm{Zr}$ and the crystalline $\mathrm{Zr}$ implies that the so-called "rule of mixtures", which is commonly employed in the estimation of elastic moduli of metallic 
glasses from those of their crystalline constituent metals, may not be applicable to a-TL-Zr alloys [35]. All elastic constants and moduli obtained for the amorphous transition metals are summarized in Table 1 and compared to their polycrystalline counterpart.

The Young's modulus $\mathrm{E}$ can be calculated from the two independent elastic constants $\mathrm{C}_{11}$ and $\mathrm{C}_{44}$ using Eqn. (2). A direct correlation is found between the shear modulus $\mathrm{G}$ and $\mathrm{E}$ for amorphous alloy films investigated in the present work, yielding a linear relationship $\mathrm{G}=0.3648 \mathrm{E}$, as shown in figure 4 . Note that the proportionality factor is slightly lower than what is widely found experimentally for polycrystalline metals $\mathrm{G} \sim 3 / 8 \mathrm{E}$ [36] or even theoretically for some orthorhombic intermetallics 0.38 [37] and fcc polycrystalline metals 0.39 [38]. But it is closer to 0.367 found in bcc [38]. One should notice that the slope is related to the Poisson ratio $v$ by Eqn. (1), then $v$ from our TFMG remains close to 0.370 in the amorphous phase.

Figure 5a displays the dimensionless quantities $C_{12} / C_{11}$ versus $C_{44} / C_{11}$, commonly referred as Blackman's diagram [29], for the Zr-TL samples. Such graphical representation is very convenient to derive trends due to the alloying effect on elastic anisotropy and interatomic bounding type, and more important in the case of the fragility index $\mathrm{m}$ [40] for metallic glasses. The dashed line (equation $\mathrm{y}=1-2 \mathrm{x} / \mathrm{A}$ ) refers to the isotropic bound to which the Zener anisotropy factor $\mathrm{A}=1$, where $\mathrm{A}=\left(2 \mathrm{C}_{44}\right) /\left(\mathrm{C}_{11}-\mathrm{C}_{12}\right)$. The solid line (equation $\mathrm{y}=\mathrm{x}$ ) corresponds to the zero Cauchy's pressure limit $p=0$. According to Pettifor, positive Cauchy's pressure $(p>0)$ is indicative of preferential metallic bonding, while negative values correspond to more directional, covalent-like bonding [39]. As intended, all Zr-TL films are located on the dashed line $(\mathrm{A}=1)$ and in the metallic bonds region $(p>0)$. Substituting $\mathrm{Zr}$ atoms by TL enables to move along the dashed line enhancing the metallic character of interatomic bonding and the ductility. The results obtained for $\mathrm{Zr}-\mathrm{Cu}$ TFMGs agree well with the ones reported on $\mathrm{Zr}-\mathrm{Cu}$ BMGs, as for example, $\mathrm{Zr}_{50} \mathrm{Cu}_{50}(\mathrm{x}=0.22$ and $\mathrm{y}=0.561)$ [41] that 
possesses a plastic deformation of about 4\%. Optimum composition is reached for the $\mathrm{Zr}_{67} \mathrm{Cu}_{33}$ film located in the top-left corner of the Blackman's diagram, which should lead to a better ductility and higher fragility index [40]. This material is close to the crystalline to amorphous transition and may be constituted of a nanocrystalline phase embedded in the amorphous matrix.

The high resolution transmission electron microscope (HRTEM) micrograph illustrated in figure $5 \mathrm{c}$ demonstrates indeed that some lattice plane fringes are observed into the amorphous matrix of $\mathrm{Zr}_{67} \mathrm{Cu}_{33}$ film. The nanodomains spotted into the diffuse matrix generate visible spots into the Fourier transform pattern. The d-spacing values found ( $2.91 \AA, 2.79 \AA, 2.48 \AA$ ) are quite close to the values corresponding to a bct-CuZr $\mathrm{r}_{2}$ intermetallic phase (ICDD card No. 18 - 0466). Moreover, in our previous study [22] related to crystallization resistance, it has been demonstrated that at 33 at.\% $\mathrm{Cu}$, the first crystallized phase at temperatures above 230 ${ }^{\circ} \mathrm{C}$ was the bct- $\mathrm{ZrCu}_{2}$ intermetallic compound. Thus, based on the HRTEM image and corroborated with the crystallization behavior [22] it can be stated that the greatest plasticity of $\mathrm{Zr}_{67} \mathrm{Cu}_{33}$ film is due the existence of the nanocrystalline domains embedded into the amorphous matrix.

The evolution of bonding character is also reflected in figure 5b, which plots the Pugh's ratio $k=\mathrm{G} / \mathrm{B}$ as a function of $p$. The $\mathrm{G} / \mathrm{B}$ ratio has been proposed initially by Pugh [28] as an indicator to link empirically the elastic moduli to the response of materials strained outside their elastic limits. Based on an evaluation of a large experimental data set on metals, Pugh initially proposed that low G/B values, i.e., $<0.571$ (for polycrystalline materials) or $<0.41$ (later extended to amorphous materials), would be associated with ductility, while higher values would reveal a brittle character. According to the Pugh and Pettifor criteria, it can be seen from figure $5 \mathrm{~b}$ that alloying enhances the ductility. In particular, $\mathrm{Zr}_{67} \mathrm{Cu}_{33}$ alloy is expected to exhibit significant shear elastic softening (-20\%) (see Fig. 4b) compared to $\operatorname{Zr}(\alpha)$. 
Nevertheless, this film exhibits a hardness to the Young modulus ratio of $\mathrm{H} / \mathrm{E} \sim 0.09$ [15] which is not satisfying the condition $\mathrm{H} / \mathrm{E}>0.1$ for improved resistance to cracking [42]. This finding suggests that criteria based only on the knowledge of elastic constants, are useful indicators to predict the plastic behavior of materials. Therefore, combining BLS and PU techniques for the assessment of the elastic properties may have strong implications in the design of thin films metallic glasses with improved toughness.

The explanation of the plastic response of a metallic glass in terms of elastic moduli has not been significantly extended beyond G/B, except for showing a further link between plasticity, Poisson's ratio [43] and the fragility index $m$ [40]. In a recent work, this issue has been clarified by introducing the cooperation parameter $\delta$ that is uniquely related to the Poisson's ratio [30]. From a thermodynamic perspective, shearing or plastic deformation is preferred in materials when fulfilling $\delta>1$ and cracking when $\delta<1$. The two modes are comparable to each other at the critical point of $\delta=1$ corresponding to the critical Poisson's ratio $v_{\text {cri }}=0.315$. It is important to underline that all our $\mathrm{Zr}$-TL studied films evidence $\delta$ values higher than 1, confirming their shearing behavior.

\section{Summary and conclusions}

Zr-TL (TL=Cu, Co and Ni) metallic glass films have been successfully deposited on $\mathrm{Si}$ substrate by dc co-sputtering. Glass formation ability is found in films with a TL content in the range of $<40-80>$ at. $\%$. The two independent elastic constants $C_{11}$ and $C_{44}$ have been selectively measured by the picosecond ultrasonics and the Brillouin light scattering techniques, respectively. Extrapolated elastic constant values from the glassy state have been identified for each pure virtual amorphous elements a-Zr, a-Cu, a-Co and a-Ni.

The combination of BLS and PU offers unique and useful opportunity to anticipate plastic behavior of thin films, based on simple elasticity criteria. In the specific case of glassy materials, only two independent elastic constants are needed and selectively measured by 
these two techniques. Through the three series of binary films, it is clearly shown that conventional representation often used for explaining the fine mechanical behavior of crystalline materials (Pugh's ratio as a function of Cauchy's pressure, Blackman's diagram and cooperation parameter) can also be successfully involved for a better understanding of plastic/elastic behavior of TFMGs. 


\section{Acknowledgement}

The authors would like to acknowledge the CLYM platform (Consortium Lyon Saint-Etienne de Microscopie, http://www.clym.fr) for the access to the 2010F Jeol TEM. 


\section{References}

[1] W. Klement, R.H. Willens and P. Duwez, Nature 187 (1960) 869.

[2] A.L. Greer, Nature Materials14 (2015) 542

[3] X.H. Du, J.C. Huang, K. C. Hsieh, Y. H. Lai, H. M. Chen, J. S. C. Jang and P. K. Liaw, Appl. Phys. Lett. 91 (2007) 131901.

[4] R. Banerjee, S. Bose, A Genc and P Ayyub, J. Appl. Phys. 103 (2008) 033511.

[5] J.S. Zhang, M. Ding and F. Pan, J. Phys. D: Appl. Phys. 33 (2000) 185.

[6] A. Inoue, Acta Mater. 48 (2000) 279.

[7] W. Chen, Y. Wang, J Qiang and C Dong, Acta Mater. 51 (2003) 1899.

[8] H.S. Chou, J.C. Huang, L. W. Chang and T. G. Nieh, Appl. Phys. Lett. 93 (2008) 191901.

[9] H.M. Chen, Y.C. Chang, T. H. Hung, X. H. Du, J. C. Huang, J. S. C. Jang and P. K. Liaw, Mater. Trans. 48 (2007) 1802.

[10] G. He, J. Eckert and W. Loser, Acta Mater. 5 (2003) 1621.

[11] R. Ristić, E. Babić, M. Stubičar, A. Kuršumović, J.R. Cooper, I.A. Figueroa, H.A. Davies, I. Todd, L.K. Varga and I. Bakonyi, J. Non-Cryst. Solids 357 (2011) 2949.

[12] Y.Q. Cheng and E. Ma, Prog. Mater Sci. 56 (2011) 379.

[13] B.F. Lu, J.F. Li, L.T. Kong and Y.H. Zhou, Intermetallics 19 (2011) 1032.

[14] P. Coddet, F. Sanchette, J.C. Rousset, O. Rapaud and C. Coddet, Surf. Coat. Technol. 206 (2012) 3567.

[15] M. Apreutesei, P. Steyer, L. Joly-Pottuz, A. Billard, J. Qiao, S. Cardinal, F. Sanchette, J.M. Pelletier and C. Esnouf, Thin Solid Films 561 (2014) 53.

[16] M. Ghidelli, S. Gravier, J.-J. Blandin, P. Djemia, F. Mompiou, G. Abadias, J.-P. Raskin and T. Pardoen, Acta Mater. 90 (2015) 232.

[17] Q. Guo, L. Zhang A. S. Zeiger, K. J. Van Vliet, Y. Li and C. V. Thompson, Scripta Mater. 64 (2011) 41. 
[18] A. Fillon, C. Jaouen, A. Michel, G. Abadias, C. Tromas, L. Belliard, B. Perrin and Ph.Djemia, Phys. Rev. B. 88 (2013) 174104.

[19] G. Abadias, P. Djemia, L. Belliard, Surf. Coat. Technol. 257 (2014) 129.

[20] P Djemia, A Fillon, G. Abadias, A. Michel and C. Jaouen, Surf. Coat. Technol. 206 (2011) 1824.

[21] P. Djemia, F. Ganot, P. Moch, V. Branger and P. Goudeau, J. Appl. Phys. 90 (2001) 756. [22] M. Apreutesei, P. Steyer, A. Billard, L. Joly-Pottuz and C. Esnouf J. Alloys Compd. 619 (2015) 284

[23] L.G. Parratt, Phys. Rev. 95 (1954) 359.

[24] C. Rossignol, B. Perrin, B. Bonello, P. Djemia, P. Moch and H. Hurdequint, Phys. Rev. B. 70 (2004) 094102.

[25] P. Djemia, F. Ganot, C. Dugautier and M Quilichini, Solid State Commun. 106 (1998) 459.

[26] P Djemia, C Dugautier, T. Chauveau, E. Dogheche, M. I. De Barros and L. Vandenbulcke, J. Appl. Phys. 90 (2001) 3771.

[27] A. Kueny and M. Grimsditch, Phys. Rev. B. 26 (1982) 4699.

[28] S.F. Pugh, Philos. Mag., 45 (1954) 823.

[29] D. G. Pettifor, Mater. Sci. Technol. 8 (1992) 345.

[30] Z.Q. Liu, W.H. Wang, M.Q. Jiang and Z.F. Zhang, Philos. Mag. Lett. 94 (2014) 658.

[31] B.R. Braeckman and D. Depla, Acta Mater. 109 (2016) 323.

[32] K. Saksl, H. Franz, P. Jóvári, K. Klementev, E. Welter, A. Ehnes, J. Saida, A. Inoue and J. Z. Jiang, Appl. Phys. Lett. 83 (2003) 3924.

[33] A. Hirata, T. Morino, Y. Hirotsu, K. Itoh and T. Fukunaga, Materials Transactions, 48 (6) (2007) 1299.

[34] U. K. Roßler and H. Teichler, Phys. Rev. E. 61 (2000) 394. 
[35] R. Ristić, J.R. Cooper, K. Zadro, D. Pajić, J. Ivkov and E. Babić, J. Alloys Compd. 621 (2015) 136

[36] C. Zwikker, Physical Properties of Solid Materials, Pergamon Press, London, (1954) p. 90

[37] N. Sebehi, Kh. Bouamama, P. Djemia and K. Kassali, Physica Status Solidi B, 253 (2015) 2769.

[38] H.M. Ledbetter, Mater. Sci. Eng. 27 (1977) 133.

[39] M. Blackman, Proc. Roc. Soc. London, Ser. A 164 (1938) 62

[40] J.D. Plummer and I. Todd, Appl. Phys. Lett. 98 (2011) 021907.

[41] P. Yu and H. Y. Bai, Mater. Sci. Eng., A 485 (2008) 1.

[42] J. Musil, Surf. Coat. Technol. 207 (2012) 50.

[43] X. J. Gu, A. G. McDermott, S. J. Poon and G. J. Shiflet, Appl. Phys. Lett. 88 (2006) 211905. 
TABLE CAPTION

Table 1: Results of extrapolated elastic constants $\left(\mathrm{C}_{11}, \mathrm{C}_{44}\right)$ and moduli $(\mathrm{G}, \mathrm{E}, \mathrm{B}, \mathrm{v})$ for pure transition metal elements $\mathrm{a}-\mathrm{Zr}, \mathrm{a}-\mathrm{Cu}, \mathrm{a}-\mathrm{Co}$ and $\mathrm{a}-\mathrm{Ni}$, considering an ideal solution behavior in the glassy state of $\mathrm{Zr}-\mathrm{Cu}, \mathrm{Zr}-\mathrm{Co}$ and $\mathrm{Zr}-\mathrm{Ni}$ thin film metallic glasses. Polycrystalline values are given for comparison.

\begin{tabular}{|c|c|c|c|c|c|}
\hline Element & $\begin{array}{c}\mathrm{C}_{11} \\
(\mathrm{GPa})\end{array}$ & $\begin{array}{c}\mathrm{C}_{44}=\mathrm{G} \\
(\mathrm{GPa})\end{array}$ & $\begin{array}{c}\mathrm{E} \\
(\mathrm{GPa})\end{array}$ & $\begin{array}{c}\mathrm{B} \\
\left(\mathrm{g} / \mathrm{cm}^{3}\right)\end{array}$ & $v$ \\
\hline $\mathrm{a}-\mathrm{Zr}$ & 84 & 17 & 47 & 61 & 0.373 \\
$\mathrm{Zr}$ & 141 & 33 & 89 & 97 & 0.347 \\
\hline $\mathrm{a}-\mathrm{Cu}$ & 184 & 37 & 102 & 135 & 0.374 \\
$\mathrm{Cu}$ & 201 & 47 & 127 & 138 & 0.347 \\
\hline $\mathrm{a}-\mathrm{Co}$ & 224 & 53 & 143 & 153 & 0.345 \\
$\mathrm{Co}$ & 296 & 81 & 212 & 188 & 0.311 \\
\hline $\mathrm{a}-\mathrm{Ni}$ & 239 & 58 & 155 & 162 & 0.340 \\
$\mathrm{Ni}$ & 295 & 83 & 216 & 184 & 0.304 \\
\hline
\end{tabular}




\section{FIGURES CAPTIONS}

Figure 1: Representative $\theta-2 \theta$ x-ray patterns of $\mathrm{Zr}-\mathrm{TL}(\mathrm{TL}=\mathrm{Cu}, \mathrm{Ni}, \mathrm{Co})$ samples as a function of TL atomic concentration.

Figure 2: Mass density of $\mathrm{Zr}-\mathrm{TL}(\mathrm{TL}=\mathrm{Cu}, \mathrm{Co}$ and $\mathrm{Ni}$ ) films measured by $\mathrm{XRR}$ as a function of TL atomic concentration. A comparison is provided to the averaged values from bulk constituents using Vegard's rule (line).

Figure 3: Longitudinal $\mathrm{C}_{11}$ and shear $\mathrm{C}_{44}$ elastic constants as a function of TL atomic concentration. A linear fit (colored on-line) of experimental results (symbols) within the amorphous region is provided and extrapolated to hypothetical a- $\mathrm{Zr}, \mathrm{a}-\mathrm{Cu}, \mathrm{a}-\mathrm{Co}$ and a-Ni. Bulk polycrystalline values are shown for comparison (colored on-line cross).

Figure 4: Shear modulus G as a function of the Young's modulus E of Zr-TL films. A linear fit (line) of the experimental results (symbols) from films with amorphous structure only, led to $\mathrm{G}=0.3648 \mathrm{E}$. The dashed line indicates the common law for polycrystalline metals $\mathrm{G}=3 / 8 \mathrm{E}$

Figure 5: (a) Blackman's diagram $\left(\mathrm{C}_{12} / \mathrm{C}_{11}\right)$ as a function of $\left(\mathrm{C}_{44} / \mathrm{C}_{11}\right)$ of the $\mathrm{Zr}$-TL films. (b) $\mathrm{G} / \mathrm{B}$ ratio of the $\mathrm{Zr}$-TL films as a function of the Cauchy pressure $\left(\mathrm{C}_{12}-\mathrm{C}_{44}\right)$. (c) HRTEM micrograph with the Fourier transform of $\mathrm{Zr}_{67} \mathrm{Cu}_{33}$ film. 




Fig1. Apreutesei et al. 


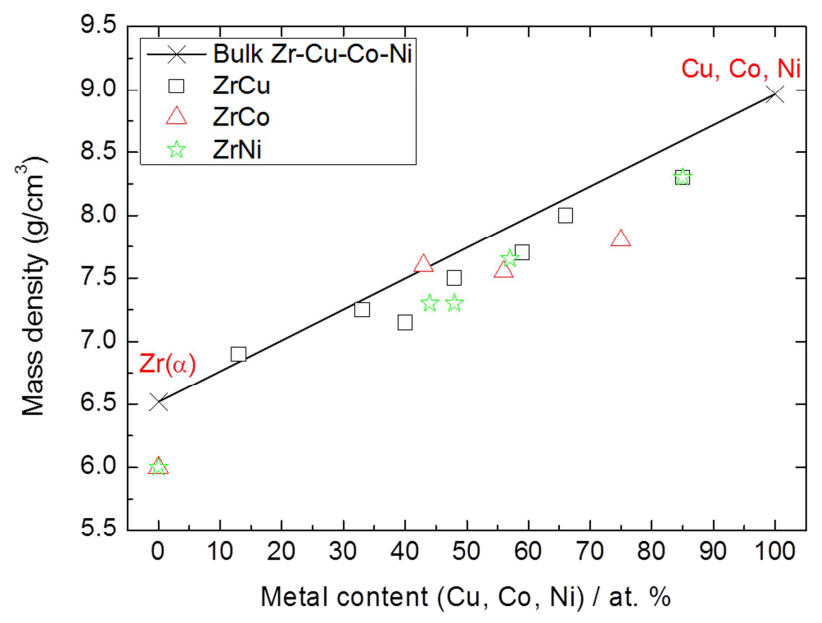

Fig 2. Apreutesei et al. 


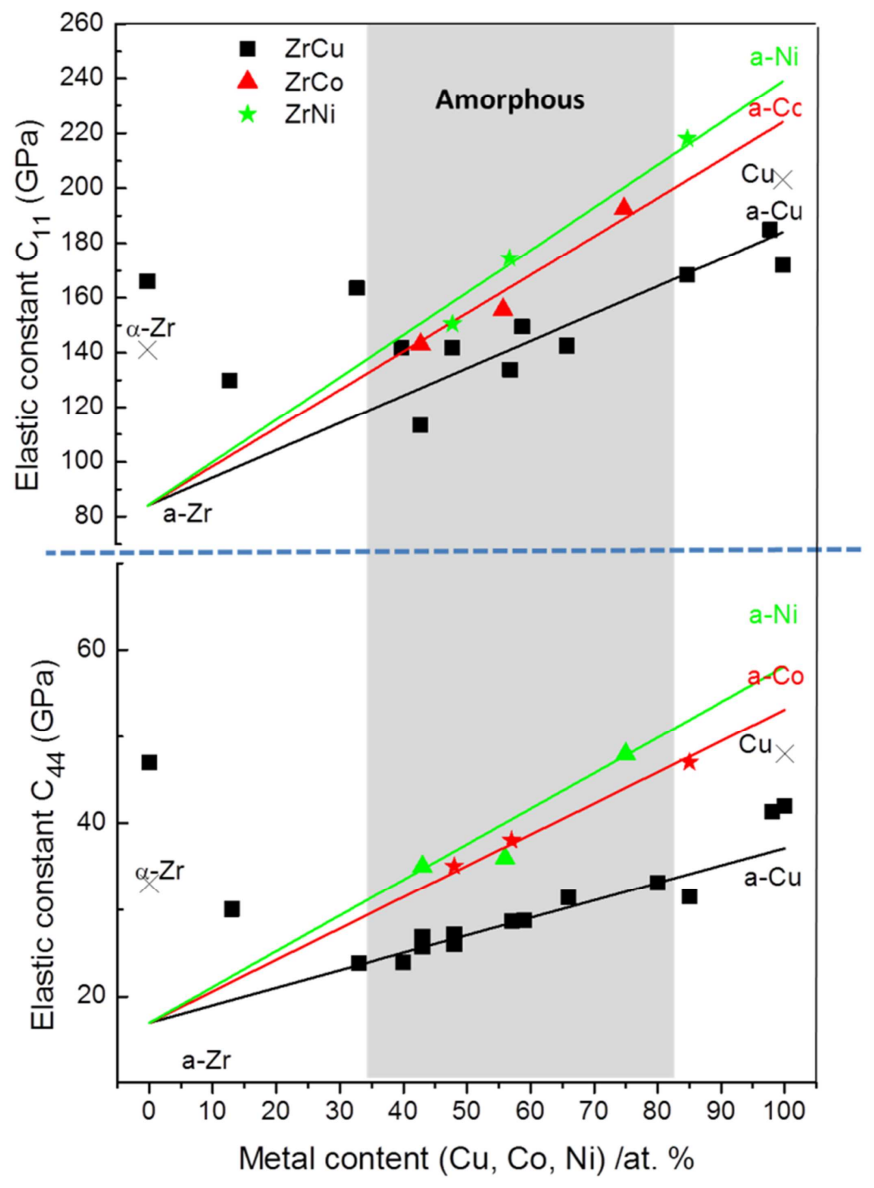

Fig 3. Apreutesei et al. 


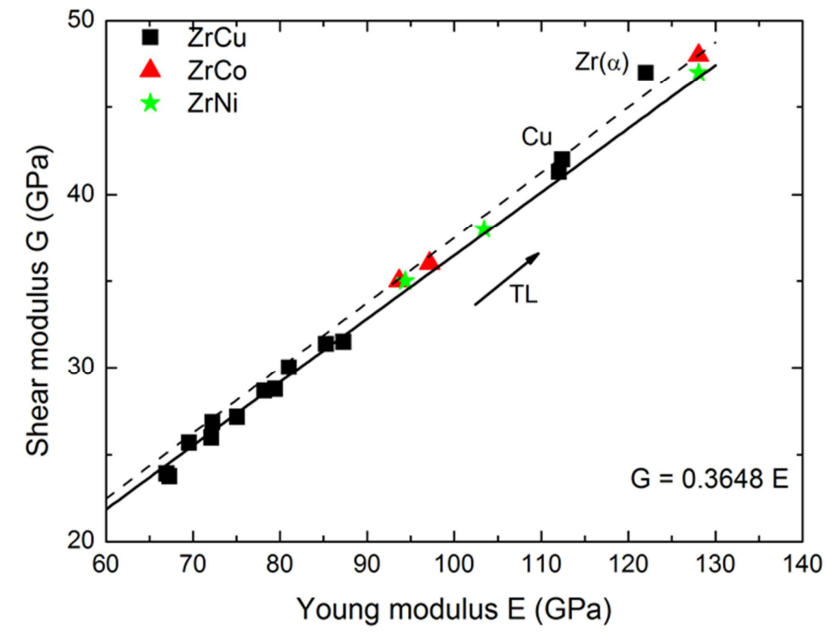

Fig 4. Apreutesei et al. 

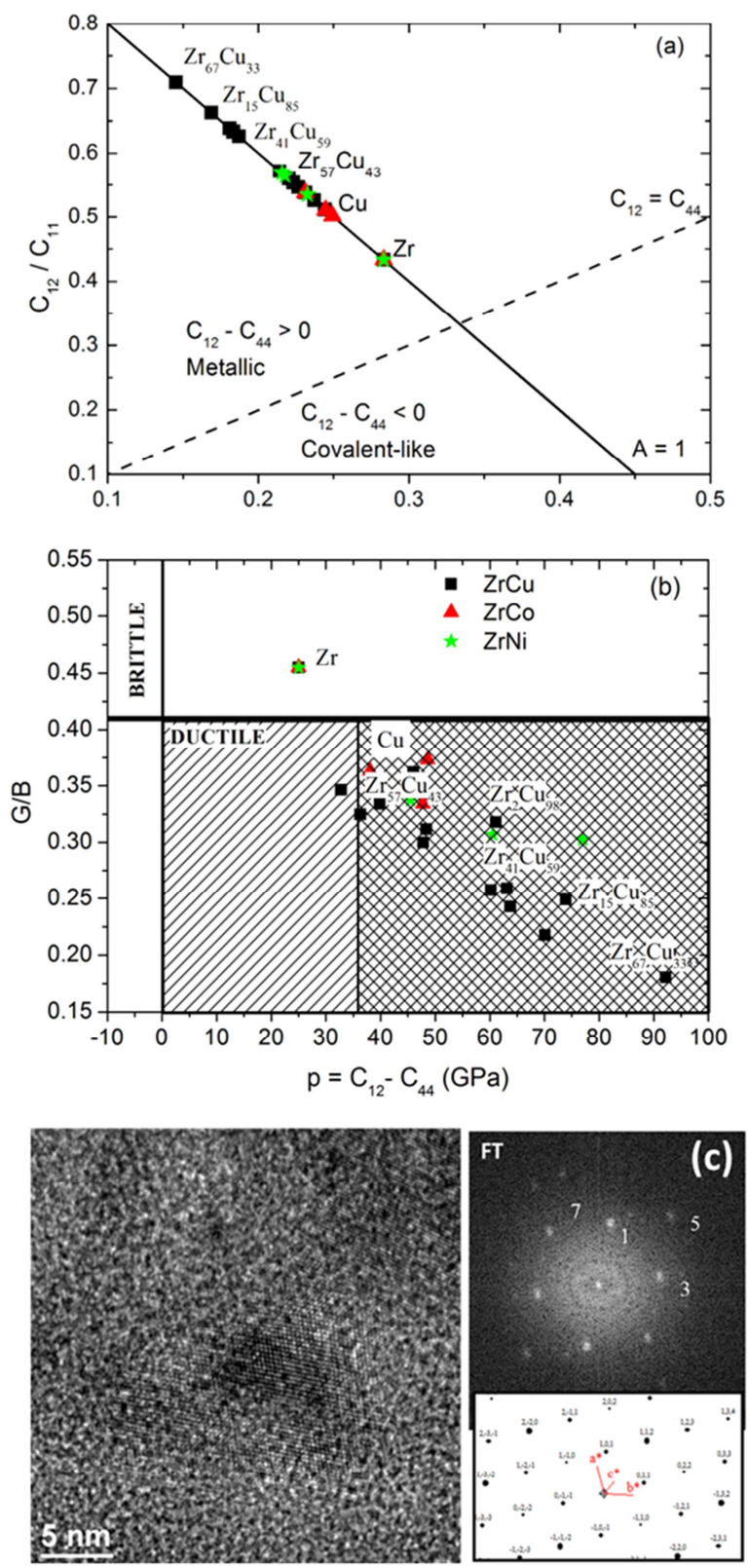

Fig 5. Apreutesei et al. 


\section{Highlights}

- Co-sputtered processing give rise to glassy $\mathrm{Zr}-\mathrm{TL}(\mathrm{TL}=\mathrm{Cu}, \mathrm{Co}, \mathrm{Ni}$ ) thin films

- Substituting Zr atoms by TL enhances the interatomic metallic bonding

- Picosecond ultrasonics non-destructive technique provided the C11 elastic constant

- Brillouin light scattering gave access to parameters like C44 elastic constant

- A ductile behavior of the thin films is predicted from elasticity measurements 